\title{
Using of Hyperbranched Poly(amidoamine) as Pretanning Agent for Leather
}

\author{
Amal Amin Ibrahim, ${ }^{1}$ Moshera S. A. Youssef, ${ }^{1}$ \\ El-Shahat H. A. Nashy, ${ }^{2}$ and Mohamed M. Eissa ${ }^{1}$ \\ ${ }^{1}$ Polymers and Pigments Department, National Research Centre, Dokki, Giza 12622, Egypt \\ ${ }^{2}$ Chemistry of Tanning Materials and Leather Technology Department, National Research Centre, Dokki, Giza 12622, Egypt
}

Correspondence should be addressed to Amal Amin Ibrahim; aamin_07@yahoo.com

Received 22 April 2013; Revised 28 July 2013; Accepted 6 September 2013

Academic Editor: Peng He

Copyright (C) 2013 Amal Amin Ibrahim et al. This is an open access article distributed under the Creative Commons Attribution License, which permits unrestricted use, distribution, and reproduction in any medium, provided the original work is properly cited.

\begin{abstract}
Although chrome is considered as the major tanning agent in the production of all types of hides and leather worldwide, it represents a serious source of environmental pollution. Therefore, polyamidoamine hyperbranched polymer (HPAM) was involved in pretanning of the depickled hides to enhance the chromium uptake during the tanning process. The key parameters which affect the exhaustion and fixation of chrome tan including shrinkage temperature of the tanned leather were studied. The results showed a significant improvement in the chrome exhaustion, the shrinkage temperature, and the texture and softness of the leather treated by HPAM.
\end{abstract}

\section{Introduction}

At the last decades, hyperbranched polymers have attracted great attention due to their dendritic architecture as highly branched polymers and their unique properties including lower viscosity, higher solubility, and higher amount of reactive terminal groups, compared with their equivalent linear analogues. Furthermore hyperbranched polymers are synthesized via one pot reaction using various techniques such as step-growth polycondensation, self-condensing vinyl polymerization, ring-opening polymerization, self-condensing ring-opening polymerization, and proton transfer polymerization [1-5]. Several types of hyperbranched polymers were prepared such as polyphenylenes, polyethers, polyesters, polyamides, polycarbonates, poly(ether ketones), and polyurethanes [6-12]. Generally, hyperbranched polymers are readily feasible for different potential applications, such as toughening and cocuring agents, multifunctional initiators, rheology control compounds for surface modification, medical applications, nanofillers for polymer nanocomposites, nonlinear optics, nanoporous generators for low dielectric constant insulators, coatings, and drug delivery systems [1324]. Therefore, hyperbranched polymers are of immense importance for industrial applications. Accordingly, this work was devoted to explore their application for further use in the leather industry as pretanning agents (modifying agent) to enhance the uptake of chrome during tanning process.

In tanning process, protein of raw hides, which is easily attacked by organisms, is converted to a stable fiber structure, preventing their putrefaction. Although several types of metallic salts are employed for tanning of leather, chromium salts are still considered as the most important tanning agents used for all types of hides and leather. Generally, chromium salts are involved in more than $80 \%$ of the tanning industry worldwide [25]. However, under normal tanning conditions, chromium salts are not completely uptaken during tanning process from the tanning bath where about $40 \%$ of chrome $\tan$ does not react with the hide proteins and discharges in the spent tanning solution as wastewater [26, 27]. Moreover, about $11 \mathrm{wt} . \%$ of the total chrome in the wet tanned leather is released during sammying, washing, and retanning processes. Therefore, the tanning operation is disposed unsafely, and it poses a threat to the environment and wastes the valuable chromium salts [28]. As a result, only $47 \mathrm{wt} . \%$ of the 
used chrome tan is fixed with leather [29]. From the environmental point of view, chromium wastes cause a serious source of pollution in the tannery effluent where the trivalent chromium $\mathrm{Cr}$ (III) thereby, which is less toxic, transforms into hexavalent chromium $\mathrm{Cr}(\mathrm{VI})$ which is very toxic for both plants and animals by oxidation in combination with other factors such as extremes in $\mathrm{pH}$ of the tanning medium [28, 30]. Accordingly, several technologies for better management of chromium salts in tanneries have been developed through high exhaustion, recovery, and recycling processes, by using efficient tanning agents as alternatives to chromium salts and/or by safe utilization and disposal of chromium-bearing wastes [31-34]. On the other hand, many attempts have been done to reduce the residual chrome in the tanning effluent by development of the primary tanning conditions and consequently to reduce the pollution of environment [35-37].

In this paper, a multifunctional aminoterminated hyperbranched poly(amidoamine) (HPAM) was used as pretanning agent to develop the conditions of tanning process and hence to improve exhaustion and fixation of chrome tan. HPAM was prepared in one pot reaction through Michael addition of methyl acrylate (MA) monomer to ethylenediamine (EDA). The modification of depickled hide by the prepared HPAM polymer, as pretanning agent, was studied as a novel process for chrome tanning operation. The factors affecting chrome exhaustion and fixation, during tanning process, as well as shrinkage temperature of the tanned leather were extensively investigated.

\section{Materials and Methods}

2.1. Materials. Ethylenediamine (EDA) and methyl acrylate (MA) monomer were purchased from Sigma-Aldrich and were used as received. Local bovine hide (virgin leather) was selected for this study. Basic chromium sulphate (BCS) of 33\% basicity (Bayer, Germany) was used as the chrome tan. All other reagents and chemicals were of pure grade and were used as received.

\subsection{Methods}

2.2.1. Preparation of Hyperbranched Poly(amidoamine) (HPAM). $0.9 \mathrm{~mL}(0.001 \mathrm{~mol})$ of methyl acrylate (MA) was added drop-wise to ethylenediamine/methanol solution ( 0.001 mole of amine in $100 \mathrm{~mL}$ of methanol) with continuous stirring for $48 \mathrm{~h}$ at room temperature. The solvent was removed from the reaction mixture under reduced pressure as previously described in the literature [38-40].

2.3. Tanning Process. The investigated raw leather samples were selected from bovine hides (depickled). The samples were worked up in the beam-house operations according to the conventional methods, as schematically illustrated in Figure 1 [41]. Briefly, depickled hides were firstly treated with $1 \%$ sodium formate solution for about 20 minutes. Afterward and before tanning process, the leather samples were treated with the prepared HPAM at different weight ratios $(3,5$, and 8 wt.\%) in aqueous media under continuous shaking for one hour. Then, HPAM-treated leather samples were treated with 12 wt.\% of chrome tan (BCS) solution with continuous shaking for $8 \mathrm{hrs}$ at room temperature. The percentages of the used reagents were calculated based on the dry weight of the depickled hide.

\subsection{Characterization}

2.4.1. Characterization of HPAM. Fourier transform Infrared spectroscopy (FT-IR) was used to verify the chemical composition of the prepared aminoterminated hyperbranched polymer (HPAM) using Jasco FT-IR-6100 spectrometer with resolution $4 \mathrm{~cm}^{-1}$ from $400-4000 \mathrm{~cm}^{-1}$. Proton nuclear magnetic resonance spectrum $\left({ }^{1} H\right.$ NMR $)$ of the prepared HPAM was recorded on Varian Mercury-Oxford-300 MZ using tetramethylsilane (TMS) as internal standard with $\mathrm{CDCl}_{3}$ as deuterated solvent. Gel permeation chromatography (GPC) coupled with refractive index (RI) detector was used to determine the number average molecular weight $\left(\bar{M}_{n}\right)$ and the polydispersity index (PDI $=\bar{M}_{w} / \bar{M}_{n}$ ) of the prepared hyperbranched polymer (HPAM). Samples were dissolved in N, $\mathrm{N}$-dimethyl formamide (DMF) as the eluent. Measurements were carried out at $50^{\circ} \mathrm{C}$ with eluent flow rate $0.7 \mathrm{~mL} / \mathrm{min}$ and injection sample volume $25 \mathrm{~mL}$. GPC instrument used in the measurements was a modified HPLC, Waters 600 System Controller, 717 plus Autosampler; Columns: PhenomenexPhenogel $10 \mathrm{um} 500 \mathrm{~A}, 250 \times 8 \mathrm{~mm}$ PhenomenexPhenogel 5 um 50 A, $300 \times 7.8 \mathrm{~mm}$; Detection: Waters model 2410 Refractive index, ATTN $=16 x$.

2.4.2. Characterization of Tanning Process. Chrome exhaustion and fixation during tanning process are of paramount importance for evaluating performance, monitoring the quality of the tanned hide, and for controlling the remained chrome in the spent liquor. Chrome exhaustion was determined by measuring the chrome content in the tanning bath effluent, after tanning process, using atomic absorption (AA) measurement where the percentage of chrome fixation by leather was determined by immersing the tanned leather in deionized water for 3 days. Afterward, the released chromium in the solution was determined via Varian atomic absorption spectrometer (Specter AA 220). Acetylene/nitrous oxide flame was used with fuel flow rate of $4.51 \mathrm{~min}^{-1}$ and oxidant flow rate of $3.51 \mathrm{~min}^{-1}$. Chrome was measured in the peak height mode at $357.9 \mathrm{~nm}$, and deuterium background correction was applied for background fluctuation. The detection limit achieved with this line at the used operating conditions was $9.07 \mu \mathrm{g} \mathrm{mL}^{-1}$ with a linear dynamic range between 0.1 and $10 \mu \mathrm{g} \mathrm{mL}^{-1}$. The recorded values are the average of three measurements.

Examination of the leather samples was carried out via scanning electron microscopy (SEM) where circular-shapeed specimens of $10 \mathrm{~mm}$ diameter were cut from the leather samples before and after treatment with HPAM and from chrome tanned leather after treatment with HPAM. These specimens were subjected to sputter-coating (Edwards's model S 140A) of gold ions. Then, the sputter coated samples were scanned with JEOL Model JSM-T20 SEM. 


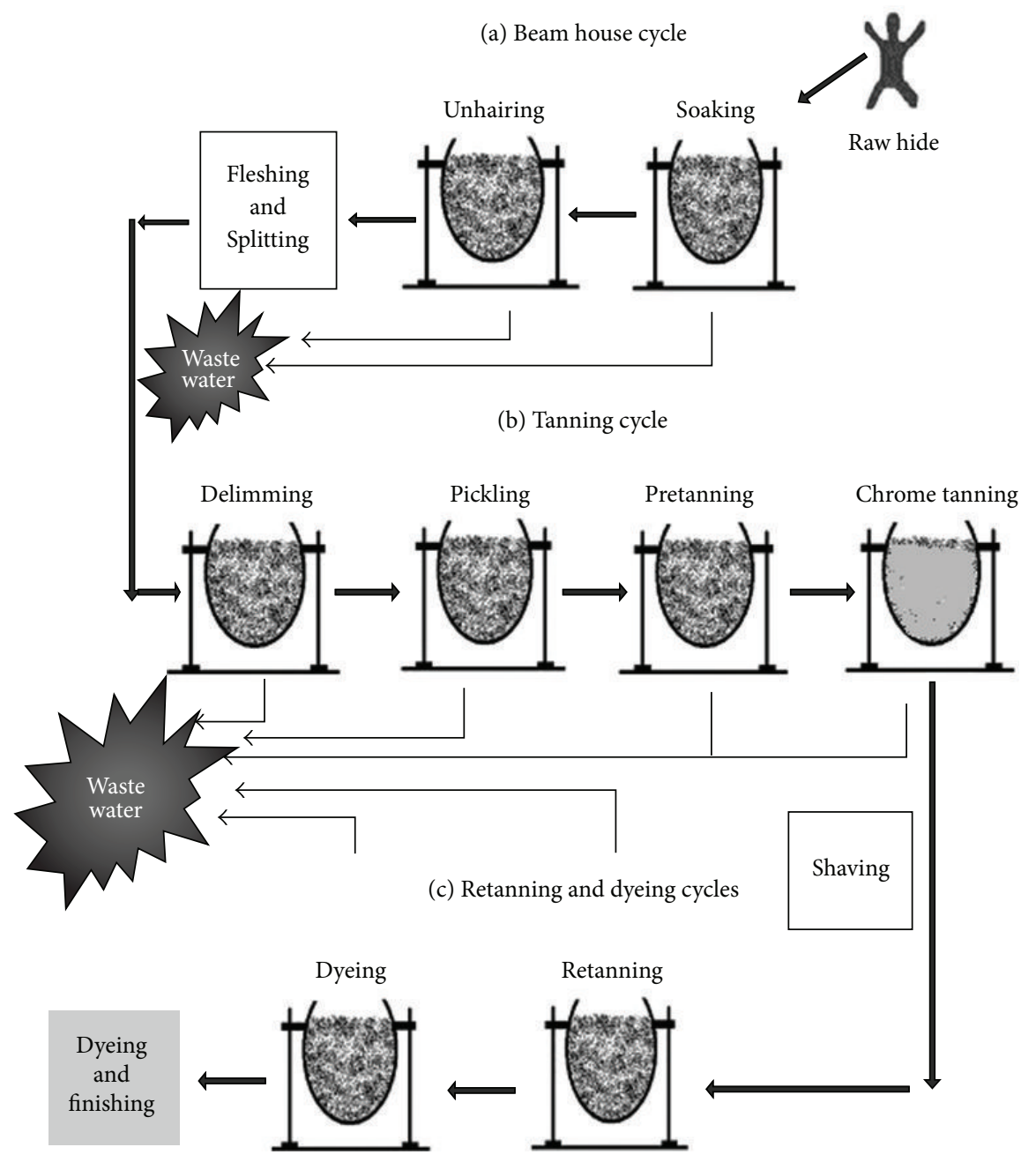

FIGURE 1: Schematic presentation of the typical processing routes for leather tanning and finishing, which consist of three main cycles: (a) beam house cycle, (b) tanning cycle, and (c) retanning and dyeing cycle. The leather samples were collected at the retanning and dyeing cycle, where $40 \%$ of chrome is disposed directly to the environment. Reported with permission [41]. Copyright 2012, Elsevier.

Shrinkage temperature $\left(T_{s}\right)$ is considered as an important parameter, which gives an indication about the efficacy of the tanning agent, where $T_{s}$ is the temperature at which the hide has a significant shrinkage when it exposes to a heated medium. The reaction between chrome tan and raw hides results in stabilizing the protein fibers via their crosslinking with chrome. Thus, degree of stabilization is mostly investigated by measuring shrinkage temperature of the tanned hide. $T_{s}$ was measured according to the official reported methods and standards [42-44]. The recorded value in each case is the average one of three measurements.

\section{Results and Discussion}

3.1. Preparation of HPAM. Multifunctional aminoterminated poly(amidoamine) hyperbranched polymer (HPAM) was prepared via Michael addition of methyl acrylate (MA) to ethylenediamine in one pot reaction, as shown in Scheme 1 [38]. The chemical structure of the prepared HPAM was confirmed by FT-IR, ${ }^{1} H$ NMR, and GPC analyses.
FT-IR (KBr) spectrum of HPAM is shown in Figure 2 where several characteristic bands appeared at 3286 and $3388 \mathrm{~cm}^{-1}\left(\nu \mathrm{NH}_{2}\right) ; 3090 \mathrm{~cm}^{-1}(\nu \mathrm{NH}) ; 2941$ and $2843 \mathrm{~cm}^{-1}$ $\left(\nu \mathrm{CH}_{2}\right) ; 1650 \mathrm{~cm}^{-1}(\nu \mathrm{C}=\mathrm{O})$ and $1555 \mathrm{~cm}^{-1}(\nu \mathrm{C}-\mathrm{N})$. On the other hand, ${ }^{1} \mathrm{H} N M R$ spectrum $\left(\mathrm{CDCl}_{3}\right)$ of HPAM, as shown in Figure 3, revealed chemical shifts $(\delta, \mathrm{ppm})$ at 2.41 $\left(\mathrm{NH}_{2}\right), 2.51-2.70\left(\mathrm{COCH}_{2}, \mathrm{NHCH}_{2}, \mathrm{NH}_{2} \underline{\mathrm{CH}}_{2}\right)$, and at 3.12$3.54\left(\mathrm{NCH}_{2}\right)$. Additionally, number average molecular weight $\left(\bar{M}_{n}\right)$ and polydispersity index PDI $\left(\bar{M}_{w} / \bar{M}_{n}\right)$ of the prepared HPAM were determined via GPC as $12249 \mathrm{~g} / \mathrm{mol}$ and 1.9 , respectively.

3.2. Chrome Tanning Process. As previously mentioned, the current research work was dedicated to enhance the chromeuptake of the tanning process by changing the primary tanning conditions. This target was achieved by using the prepared aminoterminated hyperbranched polymer (HPAM) as a pre-tanning agent for leather (see Supplementary Material available online at http://dx.doi.org/10.1155/2013/120656). Before chrome-tanning process, the leather samples were 


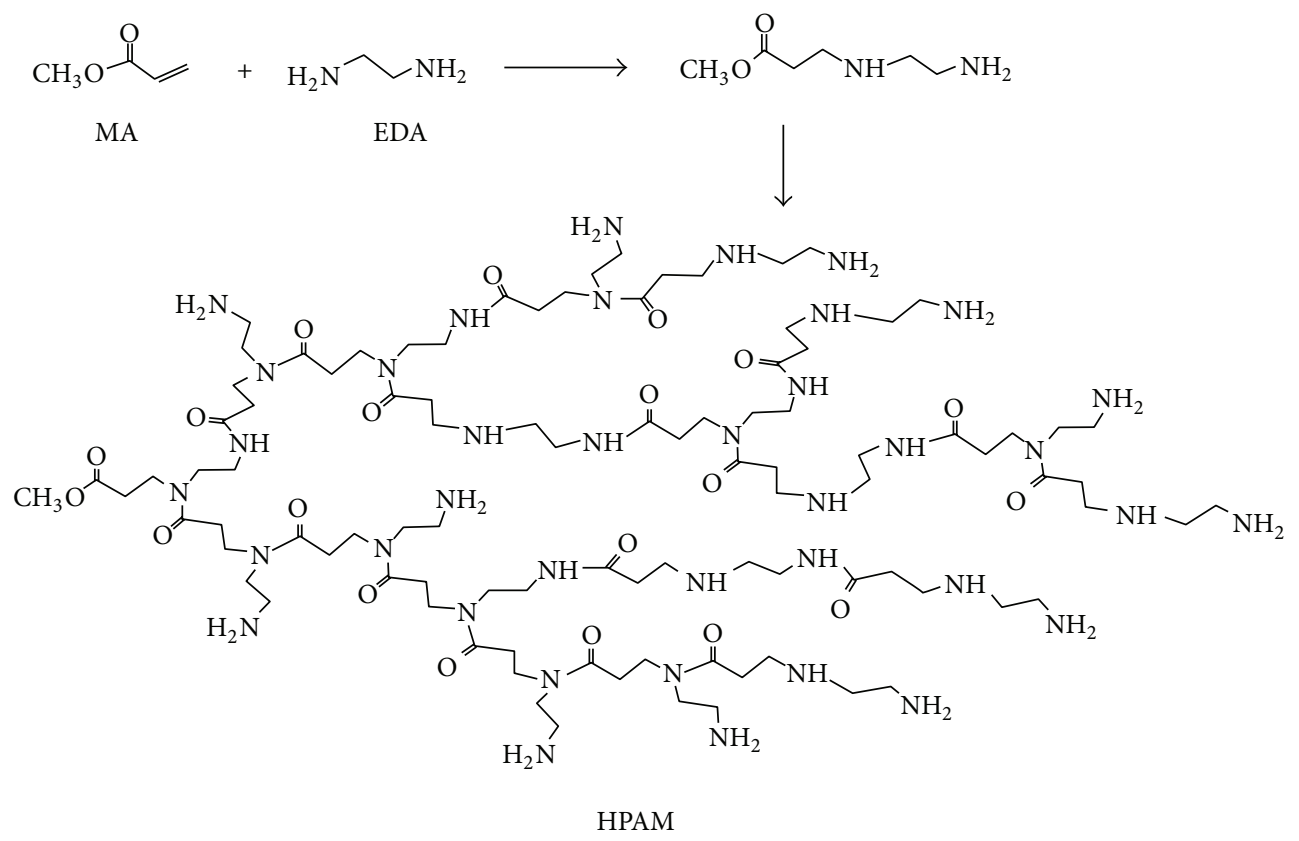

SCHEME 1: Synthesis of the hyperbranched poly(EDA-MA) (HPAM).

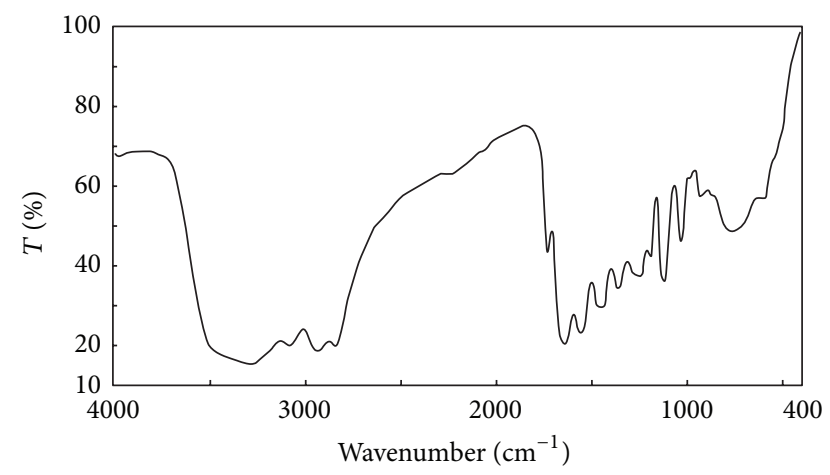

FIGURE 2: FTIR spectrum of the hyperbranched poly(EDA-MA) (HPAM).

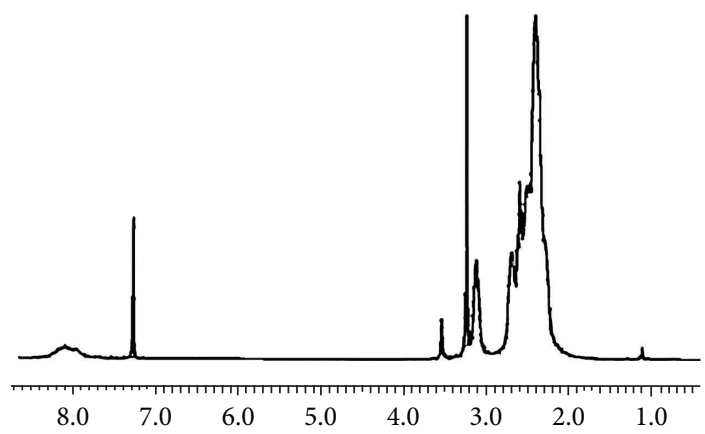

FIGURE 3: ${ }^{1} H$ NMR of the hyperbranched poly(EDA-MA) (HPAM).

immersed in HPAM aqueous solution under continuous shaking for one hour. Then, HPAM-treated leather samples were washed several times with distilled water to get rid of the unreacted HPAM with raw hides. Then, the tanning process was carried out according to the optimum conditions as reported in our previous studies $[45,46]$. Briefly, HPAMtreated raw hides were immersed in acidic aqueous solution (at $\mathrm{pH} 2.5$ ) containing $12 \mathrm{wt}$ \% basic chromium sulphate with shaking $(150 \mathrm{rpm})$ for $24 \mathrm{hrs}$. The shaking process served in flexing the raw hides and enhancing the penetration of chromium salts into the fiber structure [47, 48] allowing the chemical reactions between the chrome tan and hide proteins to take place efficiently. Also, it is worthy mentioning that the tanning process was performed at $\mathrm{pH} 2.5$ because chromium(III) tanning salts are highly soluble in strong acids but usually precipitate as chromium hydroxide or hydrated chromium oxide at $\mathrm{pH}$ values above $4.0[48,49]$, in addition to the formation of large complexes which impedes their diffusion into the raw hide [50]. The key parameters which can influence the chrome exhaustion and fixation, using HPAM aminoterminated polymer, were studied.

3.2.1. Effect of HPAM Polymer Concentration. To determine the optimum conditions for enhancing exhaustion and fixation of chrome tan, HAPM polymer was used at different concentrations $(3,5$, and 8 wt. $\%)$, as pre-tanning agent for treatment of the depickled hides, and then these samples were followed by chrome-tanning process. The samples were denoted as HP-CTL 1, HP-CTL 2, and HP-CTL 3, respectively. Chrome-tanned leather sample (CTL) untreated with HPAM was used as a blank for comparison. As clearly evidenced from Table 1 and Figures 4 and 5, the treatment of the raw hides by HAPM led to a remarkable improvement in chrome exhaustion and consequently to a drastic reduction in the residual chrome in the tanning bath. Furthermore, the optimum concentration of HPAM was found to be 
TABLE 1: Effect of HPAM content on the exhaustion and fixation of chrome tan.

\begin{tabular}{lccc}
\hline Sample code & $\begin{array}{c}\text { HPAM } \\
\text { content (wt\%) }\end{array}$ & $\begin{array}{c}\text { Chrome content } \\
\text { in the effluent } \\
\text { bath (mg/L) }\end{array}$ & $\begin{array}{c}\text { Chrome tan } \\
\text { exhaustion (\%) }\end{array}$ \\
\hline CTL (blank) & 0.0 & 1353 & 50.0 \\
HP-CTL1 & 3.0 & 7.85 & 99.4 \\
HP-CTL2 & 5.0 & 2.15 & 99.8 \\
HP-CTL3 & 8.0 & 2.77 & 99.7 \\
\hline
\end{tabular}

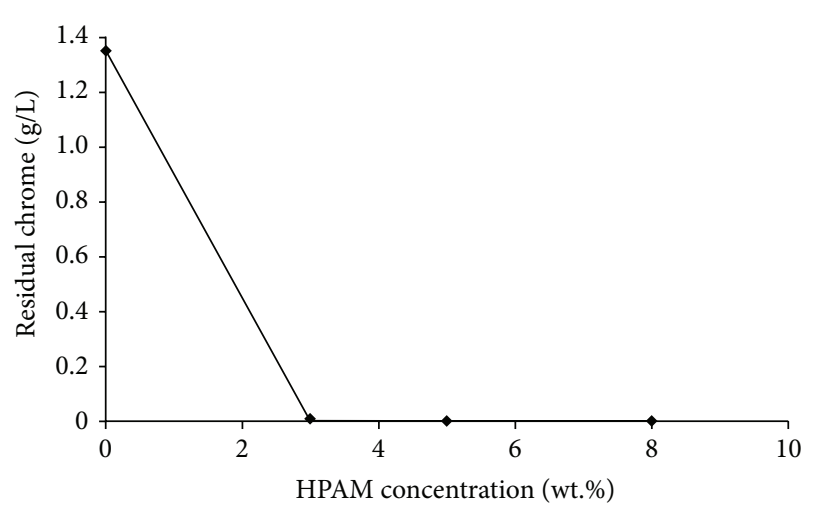

FIGURE 4: Residual chrome in the tanning bath as a function of HPAM concentration.

5.0 wt. \% which was equal to $99.8 \%$ of chrome exhaustion and $2.15 \mathrm{mg} / \mathrm{L}$ of the residual chrome in the tanning bath.

These remarkable results were attributed to the treatment of leather fibers by HPAM which imparts extra reactivity, through its reactive peripheral aminogroups with collagen fibers and consequently with more chrome salts in the tanning bath. More interestingly, it is highly favorable from the environmental point of view to reduce the amount of the residual chrome in the tanning bath, which means less pollution.

3.3. Shrinkage Temperature $\left(T_{s}\right)$. Shrinkage temperature $\left(T_{s}\right)$, as previously mentioned, is an indicative parameter for evaluating the efficiency of tanning process. In other words, it reflects the reaction between chrome tanning agent and hide proteins which results in stabilizing the fibers by crosslinking. Accordingly, the increase in $T_{s}$ of the tanned hides refers to the improvement of exhaustion and fixation of chrome during tanning process. As indicated in Table 2, $T_{s}$ of the chrometanned hides was remarkably increased by using HPAM polymer as pre-tanning agent. In addition, $T_{s}$ increased in parallel with HPAM concentration.

3.4. Investigation of the Effect of HPAM as Pretanning Agent via SEM. In order to investigate the effect of the prepared HPAM as pre-tanning agent on the grain surface and protein fiber bundles of leather, a comparative morphological study was carried out on the chrome-tanned leather before (CTL)

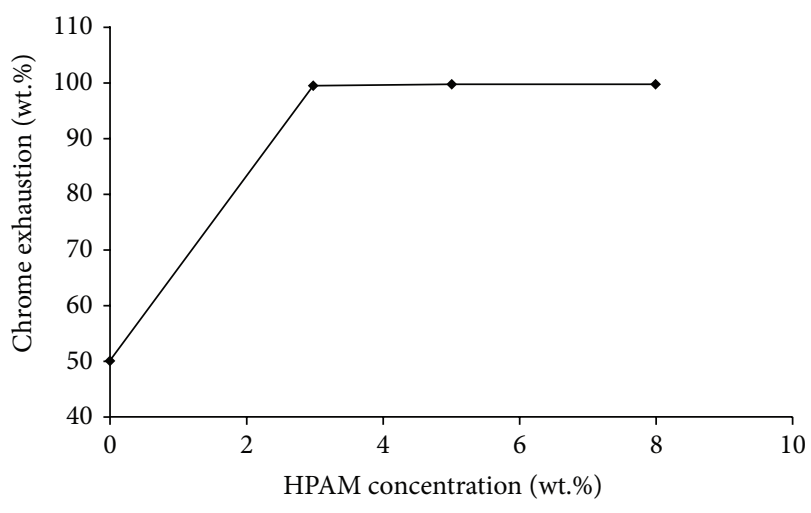

FIGURE 5: Percentage of chrome exhaustion by HPAM-pretanned leather as a function of HPAM concentration.

TABLE 2: Effect of HPAM pre-tanning agent concentration on shrinkage temperature of chrome-tanned leather.

\begin{tabular}{lcc}
\hline Sample code & $\begin{array}{c}\text { HPAM } \\
\text { content }(w t \%)\end{array}$ & Shrinkage temperature, ${ }^{\circ} \mathrm{C}$ \\
\hline CTL (blank) & 0.0 & 87 \\
HP-CTL1 & 3.0 & 98 \\
HP-CTL2 & 5.0 & 105 \\
HP-CTL3 & 8.0 & 107 \\
\hline
\end{tabular}

and after pre-tanning with HPAM (HP-CTL2). SEM micrographs of the cross-section (100x) and grain surface (50x) of CTL and HP-CTL2 samples are shown in Figure 6.

As clearly seen from Figure 6(a), the porous surface of chrome-tanned leather sample (CTL) was filled up upon treatment with HPAM (Figure 6(b)). In addition, the CTL pretanned with HPAM (HP-CTL2) had a significant improvement in softness of the grain surface, as detected by handle inspection. Furthermore, the cross-section SEM photos represented that the protein leather fibers of CTL samples (Figure 6(c)) were completely separated from each others. In the case of HP-CTL2 (Figure 6(d)), leather protein fibers aggregates were noticed and referred to the interaction of HPAM with leather protein fibers. Similar results were obtained in case of using acrylate copolymer emulsion as pretanning agent, as reported in our previous published work [51]. Generally, during tanning process, chrome $\tan (\mathrm{Cr}(\mathrm{III}))$ reacts with the polypeptide chains of leather via coordination bonds with the aminogroups of leather protein (collagen) fibers forming crosslinked structures [44]. The compatibility between chemical structure of (poly(amidoamine)) HAPM and that of leather protein fibers (polypeptides) made it suitable to be used as pre-tanning agent and improved the interaction of HPAM with the protein fibers. Accordingly, the treatment of raw hides by aminoterminated HPAM led to increasing the number of metal binding sites (amino groups) on fiber's surface, and consequently enhanced chrome tan uptake, as shown in Scheme 2. 


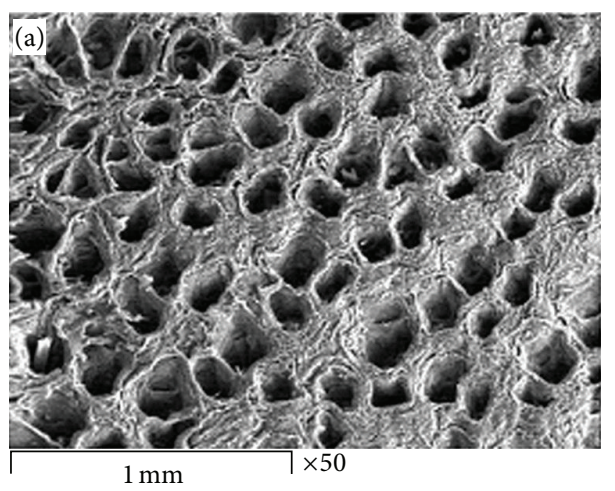

(a)

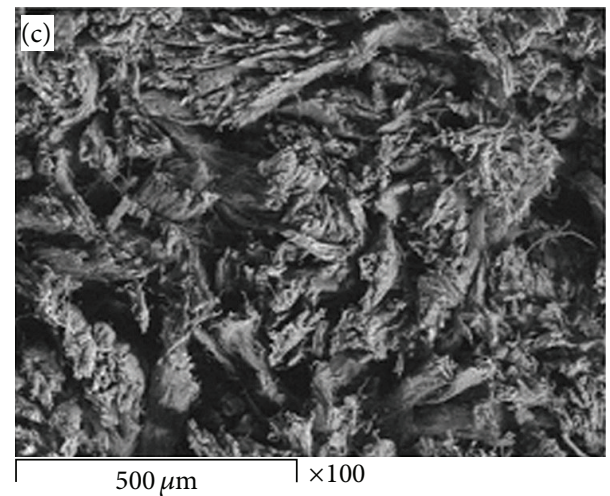

(c)

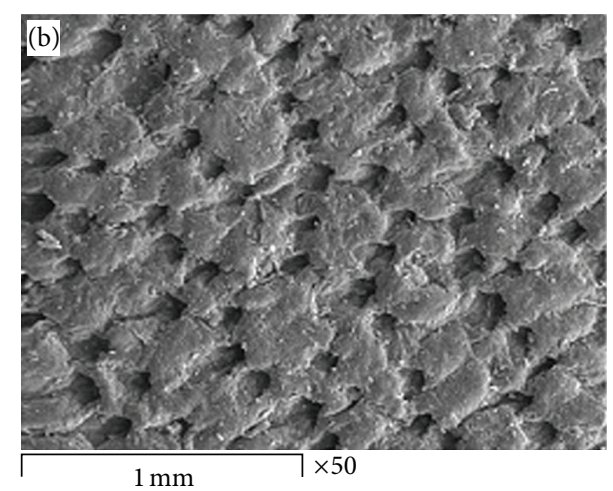

(b)

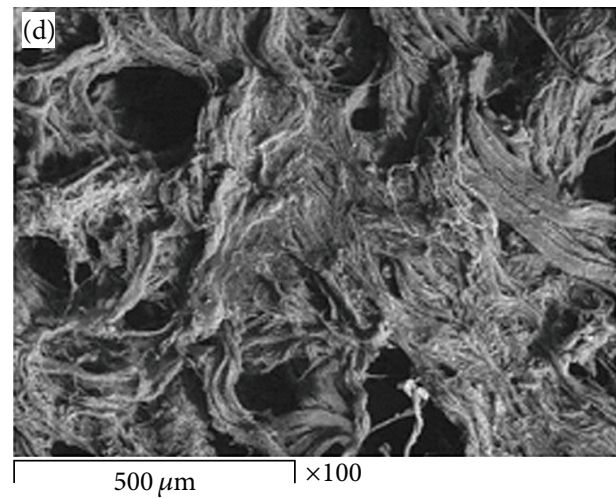

(d)

FIGURE 6: SEM photos for grain surface $(\times 50)$ of the chrome-tanned leather before (a) and after (b) pretanning with HPAM polymer and SEM photos (cross-section) of the leather samples ( $\times 100)$ showing leather protein fiber bundles of chrome-tanned leather before (c) and after pretanning with HPAM polymer (d).

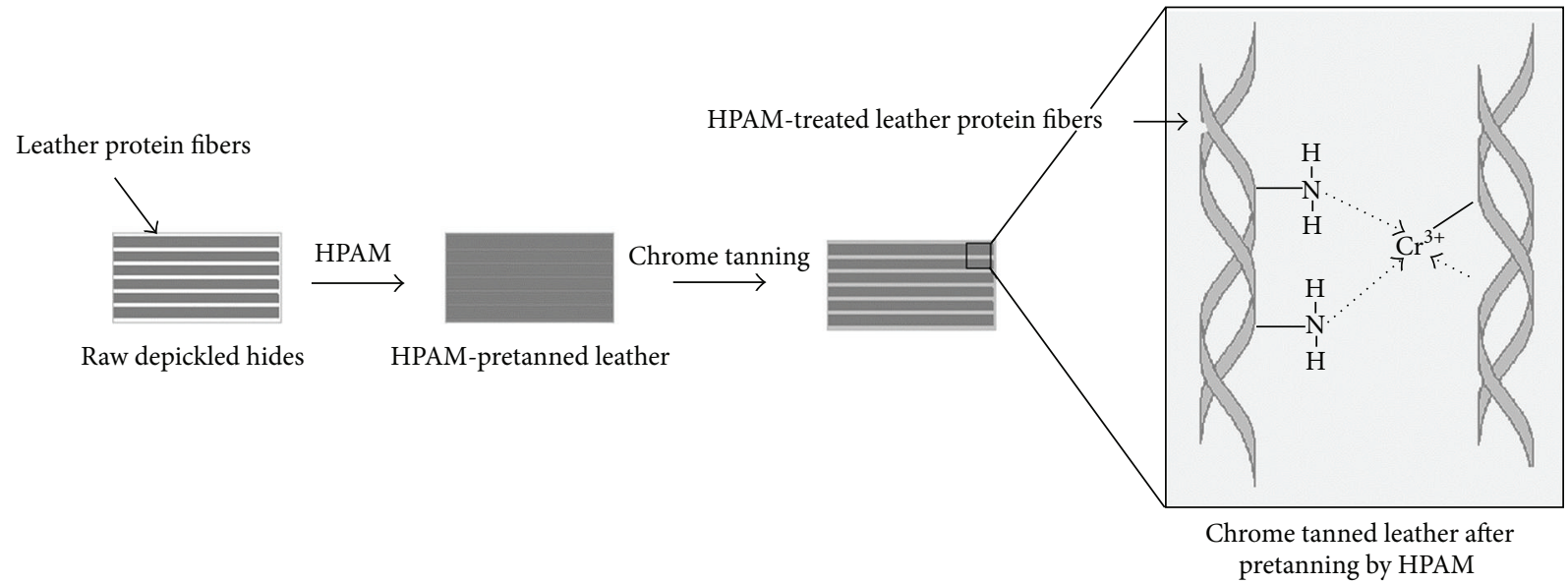

Scheme 2: Proposed mechanism of chrome tanning of HAPM-pretanned leather.

\section{Conclusions}

Aminoterminated hyperbranched poly(amidoamine) (HPAM) had remarkable effect as pre-tanning agent for leather, which led to distinct improvement in chrome fixation and exhaustion during chrome-tanning process. This in turn was reflected on the reduction of chrome loss in the tanning bath, which should have great impact on the environment. Furthermore, leather samples showed improvement in leather smoothness and soft texture upon treatment with HPAM in addition to increasing their shrinkage temperature. In fact, HPAM can be used as a multipurpose pretanning agent for leather and more interestingly, it may serve in protection of the environment from inorganic heavy 
metals like chrome which is considered as a dangerous source of pollution.

\section{References}

[1] T. Satoh, "Synthesis of hyperbranched polymer using slow monomer addition method," International Journal of Polymer Science, vol. 2012, Article ID 816163, 8 pages, 2012.

[2] J. M. J. Fréchet, "Functional polymers and dendrimers: reactivity, molecular architecture, and interfacial energy," Science, vol. 263, no. 5154, pp. 1710-1715, 1994.

[3] M. Jikei and M.-A. Kakimoto, "Hyperbranched polymers: a promising new class of materials," Progress in Polymer Science, vol. 26, no. 8, pp. 1233-1285, 2001.

[4] S. Peleshanko and V. V. Tsukruk, "The architectures and surface behavior of highly branched molecules," Progress in Polymer Science, vol. 33, no. 5, pp. 523-580, 2008.

[5] B. I. Voit and A. Lederer, "Hyperbranched and highly branched polymer architectures-synthetic strategies and major characterization aspects," Chemical Reviews, vol. 109, no. 11, pp. 59245973, 2009.

[6] Y. H. Kim and R. Beckerbauer, "Role of end groups on the glass transition of hyperbranched polyphenylene and triphenylbenzene derivatives," Macromolecules, vol. 27, no. 7, pp. 1968-1971, 1994.

[7] T. M. Miller, T. X. Neenan, E. W. Kwock, and S. M. Stein, "Dendritic analogues of engineering plastics: a general one-step synthesis of dendritic polyaryl ethers," Journal of the American Chemical Society, vol. 115, no. 1, pp. 356-357, 1993.

[8] E. Malmström, M. Johansson, and A. Hult, "Hyperbranched aliphatic polyesters," Macromolecules, vol. 28, no. 5, pp. 16981703, 1995.

[9] G. Yang, M. Jikei, and M.-A. Kakimoto, "Synthesis and properties of hyperbranched aromatic polyamide," Macromolecules, vol. 32, no. 7, pp. 2215-2220, 1999.

[10] D. H. Bolton and K. L. Wooley, "Synthesis and characterization of hyperbranched polycarbonates," Macromolecules, vol. 30, no. 7, pp. 1890-1896, 1997.

[11] A. Morikawa, "Preparation and properties of hyperbranched poly(ether ketones) with a various number of phenylene units," Macromolecules, vol. 31, no. 18, pp. 5999-6009, 1998.

[12] A. Kumar and S. Ramakrishnan, "Hyperbranched polyurethanes with varying spacer segments between the branching points," Journal of Polymer Science A, vol. 34, no. 5, pp. 839-848, 1996.

[13] M. M. Eissa, M. S. A. Youssef, A. M. Ramadan, and A. Amin, "Poly(ester-amine) hyperbranched polymer as toughening and co-curing agent for epoxy/clay nanocomposites," Polymer Engineering \& Science, vol. 53, pp. 1011-1020, 2013.

[14] D. Foix, X. Fernández-Francos, X. Ramis, A. Serra, and M. Sangermano, "New pegylated hyperbranched polyester as chemical modifier of epoxy resins in UV cationic photocuring," Reactive and Functional Polymers, vol. 71, no. 4, pp. 417-424, 2011.

[15] V. V. Tsukruk, "Assembly of supramolecular polymers in ultrathin films," Progress in Polymer Science, vol. 22, no. 2, pp. 247311, 1997.

[16] J. Zou, W. Shi, J. Wang, and J. Bo, "Encapsulation and controlled release of a hydrophobic drug using a novel nanoparticleforming hyperbranched polyester," Macromolecular Bioscience, vol. 5, no. 7, pp. 662-668, 2005.
[17] J. Xu, H. Wu, O. P. Mills, and P. A. Heiden, "A morphological investigation of thermosets toughened with novel thermoplastics. I. Bismaleimide modified with hyperbranched polyester," Journal of Applied Polymer Science, vol. 72, pp. 1065-1076, 1999.

[18] Y. Zhang, L. Wang, T. Wada, and H. Sasabe, "Synthesis and characterization of novel hyperbranched polymer with dipole carbazole moieties for multifunctional materials," Journal of Polymer Science A, vol. 34, pp. 1359-1363, 1996.

[19] J.-S. Kim, H.-C. Kim, B. Lee, and M. Ree, "Imprinting of nanopores in organosilicate dielectric thin films with hyperbranched ketalized polyglycidol," Polymer, vol. 46, no. 18, pp. 7394-7402, 2005.

[20] K. Fang, Z. Xu, X. Jiang, and S. Fu, "Preparation of amphiphilic hyperbranched polyesteramides by grafting mono methoxy polyethylene glycol onto hyperbranched polyesteramides via 2,4-tolylene diisocyanate," Polymer Bulletin, vol. 61, no. 1, pp. 63-69, 2008.

[21] L. J. Hobson, A. M. Kenwright, and W. J. Feast, "A simple "one pot" route to the hyperbranched analogues of Tomalia's poly(amidoamine) dendrimers," Chemical Communications, no. 19, pp. 1877-1878, 1997.

[22] L. J. Hobson and W. J. Feast, "Poly(amidoamine) hyperbranched systems: synthesis, structure and characterization," Polymer, vol. 40, no. 5, pp. 1279-1297, 1999.

[23] M. Sangermano, H. El Sayed, and B. Voit, "Ethoxysilyl-modified hyperbranched polyesters as mulitfunctional coupling agents for epoxy-silica hybrid coatings," Polymer, vol. 52, no. 10, pp. 2103-2109, 2011.

[24] X. Zhang, X. Zhang, Z. Wu et al., "A hydrotropic $\beta$-cyclodextrin grafted hyperbranched polyglycerol co-polymer for hydrophobic drug delivery," Acta Biomaterialia, vol. 7, no. 2, pp. 585-592, 2011.

[25] C. Bagiran, D. Brendler, and F. Wegener, "Environmentally friendly tanning composition,” US Patent 20130081211 Al, 2013.

[26] Z.-R. Guo, G. Zhang, J. Fang, and X. Dou, "Enhanced chromium recovery from tanning wastewater," Journal of Cleaner Production, vol. 14, no. 1, pp. 75-79, 2006.

[27] Z. Gao and C. Su, Treatment of Tannery Waste Water, Beijing Chemical Engineering Publisher, 2001.

[28] M. C. Chuan and J. C. Liu, "Release behavior of chromium from tannery sludge," Water Research, vol. 30, no. 4, pp. 932-938, 1996.

[29] T. C. Voice, M. L. Davis, G. B. Johnson, and L. L. Sturgess, "Evaluation of chromium recovery opportunities in a leather tannery," Hazardous Waste \& Hazardous Materials, vol. 5, no. 4, pp. 343-352, 1988.

[30] M. A. Eid, E. A. Al-Ashkara, K. A. Eid, E. H. A. Nashy, and E. H. Borai, "Speciation of chromium ions in tannery effluents and subsequent determination of Cr (VI) by ICP-AES," Journal of the American Leather Chemists Association, vol. 97, no. 11, pp. 451455, 2002.

[31] K. J. Sreeram and T. Ramasami, "Sustaining tanning process through conservation, recovery and better utilization of chromium," Resources, Conservation and Recycling, vol. 38, no. 3, pp. 185-212, 2003.

[32] M. A. Baig, M. Mir, S. Murtaza, and Z. I. Bhatti, "Laboratory scale studies on removal of chromium from industrial wastes," Journal of Environmental Sciences, vol. 15, no. 3, pp. 417-422, 2003.

[33] B. Chandrasekaran, J. Raghava Rao, K. J. Sreeram, B. U. Nair, and T. Ramasami, "Chrome tanning: state-of-art on the material 
composition and characterization," Journal of Scientific and Industrial Research, vol. 58, no. 1, pp. 1-10, 1999.

[34] T. Ramasami, "Greening of chrome tanning in Indian leather industry," ILIFO Journal of Cleaner Tanning, vol. 2, pp. 12-15, 1996.

[35] F. Silvestre, C. Rocrelle, A. Gaset, N. Caruel, and A. Darnaud, "Clean technology for tannage with chromium salts part 1: development of a new process in hydrophobic organic solvent media," Journal of the Society of Leather Technologies and Chemists, vol. 78, no. 1, pp. 1-7, 1994.

[36] K. J. Kedialya, "Recent technological progress and innovations in the application of chrome in leather making," Leather Scissors, vol. 21, pp. 1-11, 1974.

[37] B. G. S. Prasad, B. Chandrasekaran, J. R. Rao, N. K. Chandrababu, M. Kanthimathi, and T. Ramasami, "Prospects for Chromium management in Tanneries: a critical review," Leather Scissors, vol. 34, pp. 132-147, 1987.

[38] C.-H. Liu, C. Gao, and D.-Y. Yan, "Aliphatic hyper branched poly(amido amine)s (PAMAMs): preparation and modification," Chemical Research in Chinese Universities, vol. 21, no. 3, pp. 345-354, 2005.

[39] C. Gao and D. Yan, "Polyaddition of $\mathrm{B}_{2}$ and $\mathrm{BB}_{2}^{\prime}$ type monomers to $\mathrm{A}_{2}$ type monomer. 1. Synthesis of highly branched copoly(sulfone-amine)s," Macromolecules, vol. 34, no. 2, pp. 156-161, 2001.

[40] C. Gao and D. Yan, "Hyperbranched polymers: from synthesis to applications," Progress in Polymer Science, vol. 29, no. 3, pp. 183-275, 2004.

[41] L. Shakir, S. Ejaz, M. Ashraf et al., "Ecotoxicological risks associated with tannery effluent wastewater," Environmental Toxicology and Pharmacology, vol. 34, no. 2, pp. 180-191, 2012.

[42] SLTC, Official Methods of Analysis, vol. 52 of Society of Leather Trade Chemists, Redbourne, UK, 4th edition, 1965.

[43] Egyptian Standard Specifications, Chemical and biological tests of leather (ES122), 3/8/1, 1986.

[44] Egyptian Standard Specifications, Physical tests of leather (ES121), 2/2, 1986.

[45] E. H. A. Nashy, O. Osman, A. A. Mahmoud, and M. Ibrahim, "Molecular spectroscopic study for suggested mechanism of chrome tanned leather," Spectrochimica Acta A, vol. 88, pp. 171176, 2012.

[46] E. H. A. Nashy, M. H. Khedr, and N. H. El-Sayed, "Effect of different basifying agents on exhaustion and fixation of chrome tan," Egyptian Journal of Textile \& Polymer Science \& Technology, vol. 10, pp. 157-189, 2006.

[47] E. H. A. Nashy, M. H. Khedr, and N. H. El-Sayed, "Improvement of exhaustion and fixation of chrome tan by hydroxy carboxylic acids," Egyptian Journal of Textile \& Polymer Science \& Technology, vol. 11, pp. 57-70, 2007.

[48] H. P. Germann, "Chrome tannage from the viewpoint of ecology," Journal of Society of Leather Technologists and Chemists, vol. 79, pp. 82-85, 1995.

[49] T. C. Thorstensen, Practical Leather Technology, chapter 11, Krieger Publishing, Malabar, Fla, USA, 4th edition, 1993.

[50] K. H. Gustavson, The Chemistry of Tanning Process, Academic Press, New York, NY, USA, 1956.

[51] E.-S. H. A. Nashy, M. M. Essa, and A. I. Hussain, "Synthesis and application of methyl methacrylate/butyl acrylate copolymer nanoemulsions as efficient retanning and lubricating agents for chrome-tanned leather," Journal of Applied Polymer Science, vol. 124, no. 4, pp. 3293-3301, 2012. 

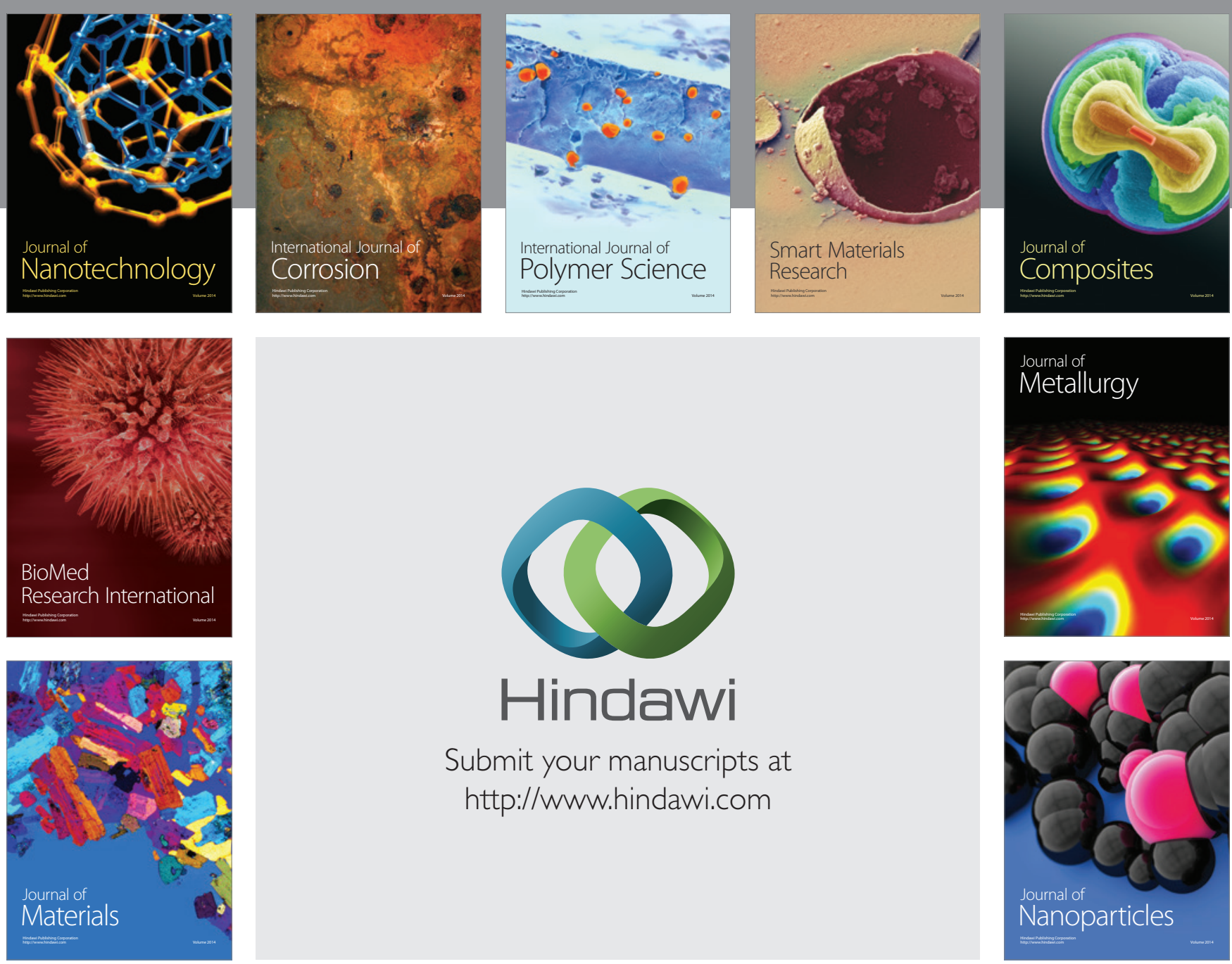

Submit your manuscripts at http://www.hindawi.com
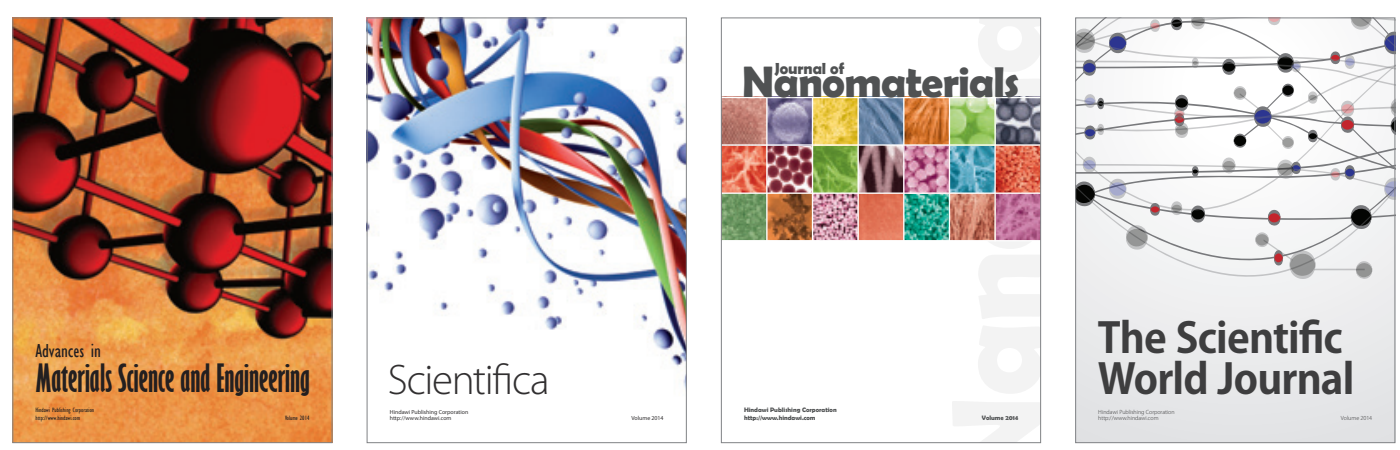

\section{The Scientific World Journal}
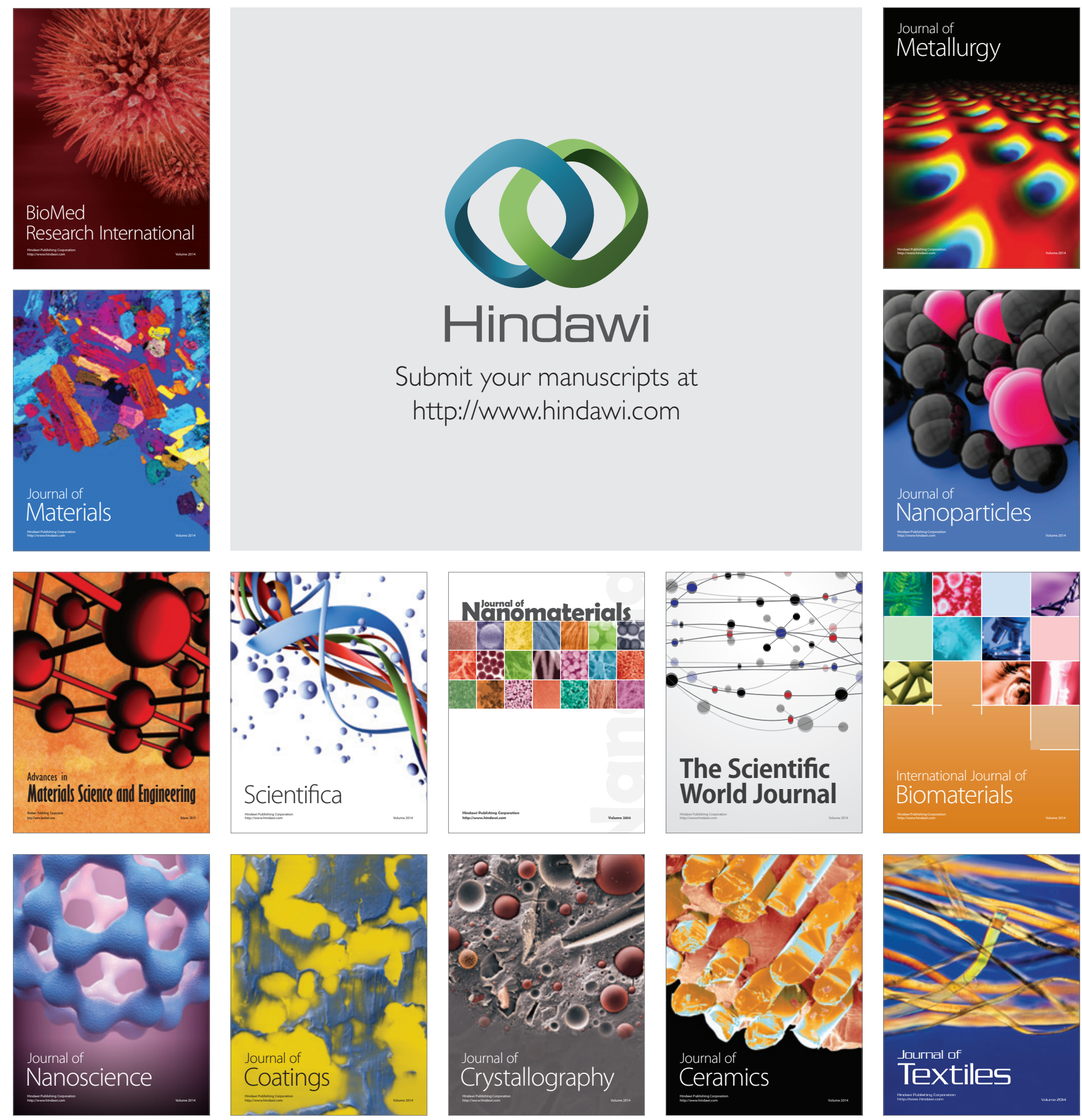